\title{
ENGLISH LANGUAGE SKILLS FOR COMMUNICATIVE PERFORMANCE AND EMPLOYABILITY- AN OVERVIEW
}

\author{
Dr. Yamini Pendyala \\ Asst. Prof In English, \\ R.V.R. \& J.C.C.E., \\ GUNTUR. \\ Mobile : 8801265258 \\ Email: Pendyala3399@Gmail.Com
}

\begin{abstract}
English has become the de-facto language for communication in these days of liberalization, privatization and globalization. It has become indispensable though there are several cultural and linguistic movements in favour of the vernacular and regional languages. English, as a language, once upon a time was considered as the exclusive privilege of the urban elite who learnt it through literature. Now, it has started percolating and making inroads into the most rural terrains also. English language is the Primary medium of instructions in academics, chief means of communication in business and industrial transactions apart from the interactive medium in job interviews. In order to be competitive in the job market and evolve out successfully in professional career, one must have a greater hold on English language and its usage. Employability can surely be achieved through the increased usage of English language. Employability is possible only through mastery over the four fundamental skills: Listening, Speaking, Reading and Writing (LSRW), in short.
\end{abstract}

Key words: Communication, cultural and linguistic movements, Language and Literature, Employability

\section{Introduction:}

'Language is the dress of thought'

- Dr.Samuel Johnson.

Communication is a very important tool in human life. It is an essential requirement in this globalised world to survive. It is no secret that today's work place is rapidly becoming vast, as the business environment expands to include various geographic locations and span numerous cultures. English is a living and vibrant language spoken by over 300 million people as their native language. The one and only language which had conquered all over the world with its charm and beauty; which has vanished the glow of other languages with its popularity and significance; which holds the dominance in all the fields with its remarkable success; which has spread the aroma of fragrance with its bank of vocabulary and stream of fluency, which has captured the eyes of millions across the globe with its magnificence and versatility is English, which has become the leader of all languages, though the youngest of all the world languages. 
English language is a store house of social and political knowledge. Without the knowledge of English language, no professional can progress. Once upon a time, English language was considered as an exclusive privilege of the educated and urban elite who learnt it through literature. But now English has become the primary medium of instruction in academics, chief means of communication in business and industrial stream and also the interactive medium in job interviews. It is the need of the hour to work on affirmative action programmes like disseminating best ELT practices with an e-culture interface and enabling current technical acumen of employability through JKC, STP, and certificate courses in communicative English and soft skills. 'Employability' is the 'ability' or 'potentiality' or 'competency' required to get a job or employment. There are four fundamental 'Skills' for acquiring 'Proficiency' in English language like it happens in other languages as well. These four skills are Listening, Speaking, Reading and Writing (LSRW), in short. It has been viewed that 'Employability not only depends on whether one is able to fulfill the requirements of specific jobs, but also on how one stands relative to others within a hierarchy of job seekers'.

Of all the four skills of language, the most neglected skill is 'listening'. 'Listening' is intensive hearing'. It is a very active and concentrated process. It is not passive as 'hearing'. Lack of interest or lack of concentration will mar the listening skills. It is a misconception that 'Communication Skills' imply only 'Speaking Skills'. In fact, the process of communication cannot be complete without 'listening skills' as the responder has to respond only after he listens to the speaker. If the 'listening skills' are not proper, the candidate will not be able to answer the interview questions effectively. He will either give wrong answers or ask the panel to repeat the question; both of which can jeopardize his claim for the job and his employability is seriously affected. This is because the candidates who are going to become future employees in the company should have good listening skills to receive several instructions, suggestions and counselling. 
The most dynamic and vibrant of all the skills is 'Speaking'. Employers or Companies during recruitment intend to select prospective employees and subject them to various speaking tests like JAM, EXTEMPORE, DEBATE, GROUP DISCUSSIONS etc., to test their exact ability. In order to cope with JAM, one should develop the ability to think spontaneously on one's feet. There is no necessity to think unnecessarily about delivering a long speech. But, it is important to gather few ideas and use linkers like at first, secondly, next, after that, however, finally, in order to, therefore, as a result, at last, to conclude etc. to present the ideas or views in a systematic manner.

The greatest advantage of practicing JAM is that it will facilitate the ability to quickly respond to the question / topic / issues. While practicing speaking activities, one must have the ability to raise questions by oneself so as to enable to gather points. JAM helps us a lot to develop fluency. 'Speaking' can really 'impress', 'inform', 'educate', create awareness', 'inspire' and 'entertain' by enhancing one's chances of selection. While speaking, there should be natural flow from one point to another to see that the interest of the audience does not waive. This is called 'transition', for ex, using expressions like, "having discussed a few advantages of social networking sites, let me move to disadvantages". This will make the audience understand what has been covered until then and what is to be thereafter.

'Voice modulation' is an important part of 'speaking'. Modulating the speech through tone, tempo, pauses and emphasis improves clarity in communication. 'Tone' is the 'feeling expressed through one's voice'. The tone should not be too soft, loud or too harsh. It is often seen that the students/candidates, while attending interviews, talk either too fast or too slow. Sometimes, they combine long sentences together while the next time, they breakup the same sentence into pieces. The speed of one's thoughts is so high that sometimes one struggles to get the right words and starts fumbling. This happens especially when one thinks in one's mother tongue and speaks in English. Fillers like, 'Ah', 'Uh', 'Umma', 'You see', 'eh, eh', 'So', etc should be avoided. 
ELK

Asia Pacific Journals

To be a good speaker or effective communicator or to enhance one's employability, one has to -

i. Be clear in thoughts and words.

ii. Arrange ideas logically and they should not be haphazard.

iii. Maintain audibility.

iv. Maintain eye-contact with the audience/panel members.

v. Practice speaking before mirror, or before a small group of 2 to 4 to muster confidence.

vi. Use appropriate words at contexts. To do this develop vocabulary usage by constantly referring to dictionary.

vii. Use relevant facial expressions and body language in lieu with the content being spoken.

Reading skills which are tested not only during competitive examinations but also 'Recruitment process' are so important. 'Comprehension testing' has become a key feature now- a-days and answers have to be identified correctly within less period of time. So, when 'accuracy' and 'speed' are the parameters 'competent reading' becomes essential. It
ELK Asia Pacific Journals - Special Issue

ISBN: 978-81-930411-1-6

involves understanding literal and applied meanings. Most of the students falter to answer this section, thus sending a signal, that, in future, they cannot comprehend various documents and reports of the companies or anything that is written to be read. This will seriously mar their 'employability'. These skills are the foundation blocks for career building. The ability to read with understanding, also known as reading comprehension is critical to successful employment. If one cannot fully understand the instructions on how to apply for a job, one is at a disadvantage. Many jobs require reading as a part of their duties. There are reports, memos, e-mails and safety requirements that are part of day to day functions of the job. Poor reading skills will cause one to lag behind other workers because it takes one more time to understand and interpret what one is reading". The students should be in a position to identify the main idea or the writer's purpose, choose a phrase that best restates an idea in the passage, define a word based on its meaning in the passage, picking up information from the passage etc. The techniques/strategies to be adopted to become a good reader are : 
Skimming - This means reading through the passage quickly. It is done to reorient oneself to the text. Once one orients oneself to the text, the next step is to identify the main ideas in the passage. Every paragraph in the passage has its own idea, which is supported by examples or by further explanation. Scanning - This is a strategy used to locate specific information, may be numbers (statistical data), one word substitutes, the reasons/causes that are mentioned for a phenomenon, synonyms or antonyms etc. Drawing Inferences - This is intended to fill in the gaps with logical assumptions based upon clues from the passage. This strategy rests on 'Evidencebased guessing'. The student has to guess the meaning of a word based on the context in which it is used.

Reading Skills can be improved by regular reading of newspaper, magazines, journals, novels not only for seeking information or for entertainment but also to have critical perspective which will enhance one's grasp on one's inferencedrawing ability. While reading, one should read in 'chunks' (group of words at a time) and not word by word as it will hamper the rate of reading and will slow it down.
The next important skill is 'Writing'. A good piece of writing should have a clear purpose, provide complete message/information. Writing is a permanent record of facts, experiences and events. Through writing, one is able to share ideas with people across the globe, support statements, arouse feelings, persuade and convince people. Francis Bacon, known as the father of essays, had rightly remarked, "Reading maketh a full man, conference a ready man and writing an exact man". It is only by writing that we make ourselves quite clear. As one has time at one's disposal in the activity of writing, one can provide examples, illustrations, facts, statistics, anecdotes, causes, effects, reasons, predictions, suggestions etc. Writing, in one way, is, 'speaking delayed'.To improve one's writing skills, one should practice writing essays on wide variety of topics/issues. 'Brain Storming' is a useful activity to think for ideas especially when one is dealing with 'imaginative topics'. 'Mind Mapping' is a technique for making notes before writing. This will provide enough material/content for one if one is basically deficient in that. The main idea can be written in the centre. This idea can be developed by making associations with its 
ELK

Asia Pacific Journals

branches out in different directions. For Example, instead of simply asking the students to write an essay on the Advantages and Disadvantages of Computers, they can be given a 'MindMap' of this sort which will generate further ideas in them and makes them form sentences.

A third technique is 'Questionnaire method' where one uses a series of questions to stimulate one's thinking about what one has to write. One can even use 'Tree-Diagrams' if the subject demands an essay to describe some 'Classification' or 'Flow-Chart' if it demands describing the 'Process' of something. "Being able to demonstrate to employers good written and interpersonal skills at the initial stage of recruitment would demonstrate convincingly to an employer that you have an essential basic life-skill in which to succeed in a graduate position".

It is always to be understood that these four skills are not 'mutually exclusive'. They are interdependent. Proficiency in one skill may pave a way for enhancing other skills, for instance, it is said that a 'good reader is generally a good writer' and a 'good listener is generally a good speaker.' If these four English
ELK Asia Pacific Journals - Special Issue ISBN: 978-81-930411-1-6

Language skills are mastered, then one's 'Employability' will ascend.

\section{References:}

[1] Alan Pritchard. Effective Teaching with Internet Technologies. British Library, 2007. Print.

[2] Brown, P. and Hesketh, A. The Mismanagement of Talent: Employability and Jobs in the knowledge Economy. Oxford: OUP, 2004. Print.

[3] Brumfit, C.J. and Johnson, K. Communicative Approach to Language Teaching. C.U.P. 1979 Print.P.Tench, London and Basingstoke: Macmillan, 1981.

http://www.careers.salford.ac.uk/page/co mmunication. 